NOTICE: this is the author's version of a work that was accepted for publication in Atmospheric Environment. Changes resulting from the publishing process, such as peer review, editing, corrections, structural formatting, and other quality control mechanisms may not be reflected in this document. Changes may have been made to this work since it was submitted for publication. A definitive version was subsequently published in Atmospheric Environment, Vol. 79 (2013). 10.1016/j.atmosenv.2013.07.011 


\title{
Assessment of polyaromatic hydrocarbon emissions from laser printers
}

\author{
Benjamin J. Mullins ${ }^{\mathrm{a}, \mathrm{b}, \mathrm{c}}$, Dean Bertolatti ${ }^{\mathrm{a}}$, Ryan Mead-Hunter ${ }^{\mathrm{a}, \mathrm{b}, *}$ \\ ${ }^{a}$ Curtin Health Innovation Research Institute, Curtin University, U1987, Perth 6845, \\ WA, Australia \\ ${ }^{b}$ Fluid Dynamics Research Group, Curtin University, U1987, Perth 6845, WA, Australia \\ ${ }^{c}$ Atmospheric Environment Research Centre (AERC), Griffith University, Nathan, 4111, \\ Qld, Australia
}

\begin{abstract}
The potential for polyaromatic hydrocarbon (PAH) emissions from laser printers has been examined using a simulated printing process and a detailed chemical analysis of printer toner. We have analysed the PAH content of both carbon black (a toner constituent) and toner before and after heating and have found measurable evaporation and subsequent condensation of PAHs. Based on our analysis we have estimated a maximum possible PAH emission rate of $82.1 \mu \mathrm{g} /$ minute of printing for a $10 \%$ page coverage. Our VOC emission results agree well with those of other authors. The concentrations of individual PAHs in the emissions were relatively low, however non-trivial, especially long term.
\end{abstract}

Keywords:

PAHs, VOCs, toner, ultrafine particles, printing

\section{Introduction}

Laser printing devices are common in workplaces, libraries and in homes. There has recently been concern over the health effects of such printers; specifically the generation of ultrafine particulate matter during the printing process. This has in turn prompted a resurgence in inkjet technology. A number of studies have measured the particle concentrations produced by

\footnotetext{
${ }^{*}$ Corresponding author. Telephone +6189266 3013, Fax +61892662358

Email address: r.mead-hunter@curtin.edu.au (Ryan Mead-Hunter)
} 
laser printers (He et al., 2007; Schripp et al., 2008; Wensing et al., 2008; Morawska et al., 2009; Koivisto et al., 2010; Wang et al., 2011; Tang et al., 2012b), while others have assessed the risk of such exposures (Hänninen et al., 2010). A comprehensive study by He et al. (2007) found that a large proportion of commercial laser printers generated ultrafine particles and that around half of those that did, did so at high concentrations.

This potentially represents a health risk as there is growing evidence to suggest that the surface area of carbon nanoparticles (like those generated by heating toner in the printing process) is the most toxicologically relevant factor (Stoeger et al., 2006). Though at this stage there is little epidemiological evidence linking printer emissions to health problems (Hänninen et al., 2010).

However, work with human lung cell cultures has found that both printer toner and printer emissions have a genotoxic effect (Gminski et al., 2011; Tang et al., 2012a; Könzcöl et al., 2013). The exact component(s) of printer toner which cause this effect are, however unclear as there are many volatile organic compounds (VOCs) and polyaromatic hydrocarbons (PAHs) present in printer toner. The presence of such compounds is an artifact of the production of carbon black (a key component in toner) via combustion in substoichiometric air. Additionally, the particles emitted during the printing process contain inorganics, such as iron, silicon and bromine (Barthel et al., 2011).

Depending on the temperature reached during the printing process, these VOCs and PAHs may be released. He et al. (2010) studied the effect of fuser roller temperature in laser printers and found that it was the most significant factor in terms of the number of particles generated.

Given that laser printers are almost exclusively used indoors, there will be a risk of exposure to printer emissions and as such consideration must be given to printer emissions when monitoring indoor air quality. Kagi et al. (2007) considered the implications of both chemical and ultrafine particles for indoor air quality. While some studies have measured and identified VOC emissions from office equipment (such as printers and photocopiers) (Lee et al., 2001; Lee and Hsu, 2007), as well as considering health impacts (Lee et al., 2006; Wolkoff and Nielsen, 2001), to the best of our knowledge no study has identified the compounds present in emissions from laser printers.

The presence and release of PAHs in and from toner is important as a large number of PAHs are classified as carcinogens or probable carcinogens (Straif et al., 2005). This work examines the release of PAHs from toners using 
a simulated printing process, to identify compounds that may be released during the printing process, as well as the PAHs that are present in toner.

\section{Methods}

Our "simulate" printing (or toner heating) methods emulate the evaporationcondensation processes which are likely to occur on the fuser-roller of a laser printer. We neglect the additional forces (mechanical and electrostatic) which exist in a printer. We also do not have a sorbent substance (paper) present. The heating rates in our system were necessarily slower than in a real printer, and the toner mass higher per unit area. However, we believe our system accurately replicates the evaporation of PAHs and SVOCs from toner, if not the fate once released. Our two methods (TGA and large scale) produced almost identical mass losses of toner, despite different heating rates, which supports this conclusion. Most studies of printer emissions (Morawska et al., 2009; He et al., 2007; Wang et al., 2011) have found a spike in particulate emissions at the commencement of the printing process, which rapidly diminishes after approximately $30 \mathrm{~s}$. This suggests that SVOCs and PAHs may possibly deposit on the fuser roller (or other printer components), and be re-released at the start of the printing process.

Given that the release of ultrafine particles during a single printing operation is relatively low, and that PAHs only make up a small fraction of the toner constituents, identifying individual components in the emissions would be difficult. Therefore, this work has utilised a simulated printing process whereby a sample (either toner (Black MP C5503, RICOH,USA), or carbon black (Printex U, Degussa, Germany) (Bredin et al., 2011)) is heated rapidly, using a Thermogravimetric Analyser (TGA, NETZSCH Tarus TG209 F3). This allows any mass loss from the toner due to heating to be measured.

A series of measurements were made using the TGA, with samples (10-30 $\mathrm{mg}$ ) of either toner or carbon black, with one of three different temperature profiles. All measurements were preceded by a 45 minute purge of the sample chamber with either air or nitrogen at $38^{\circ}$. The first set of measurements was conducted by heating at $50^{\circ} \mathrm{C} / \mathrm{min}$ to a temperature of $250^{\circ} \mathrm{C}$. The TGA was then held isothermal for 5 minutes before the temperature was returned to $38^{\circ} \mathrm{C}$ as quickly as possible. The purpose of this rapid cooling is to give as close an approximation to the printing process as possible.

The second set of measurements the TGA was held isothermal at $250^{\circ} \mathrm{C}$ for 1 hour, before being allowed to return to the ambient temperature. 
The final set of measurements considered mass loss at different maximum temperatures. In these measurements, the toner was heated to temperatures of $150,200,250$ and $300^{\circ} \mathrm{C}$ and then allowed to return to ambient temperature as quickly as possible.

In order to allow the results of the simulated printing process to be related to actual printing, we evaluated the toner consumption for a printer, by printing 100 identical pages and determining the mass loss of toner from the cartridge. For this work we used a FujiXerox DocuCentre IV C 3375, multifunction printer. These measured values, combined with measured emissions in other work were then used to calculate emission rates.

Additional experiments were also conducted using larger size toner samples $(1 \mathrm{~g})$ in a glass vessel. This set up involved drawing emissions from heated toner through a filter. The set-up is shown in Figure 1.

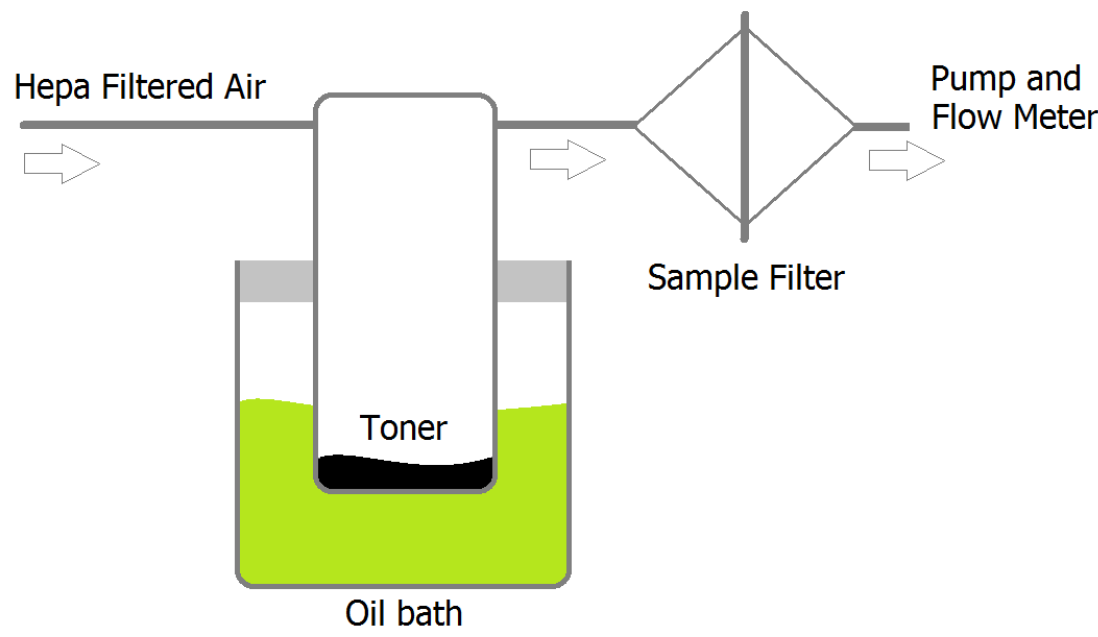

Figure 1: A schematic of the experimental set up for the large scale experiments

In order to maintain an evenly distributed and stable temperature a sand and avocado oil bath was used to heat the glass vessel containing the sample (Figure 1). The emissions from the heated toner were passed through a glass fibre filter. The oil bath was pre-heated to $230-250^{\circ} \mathrm{C}$, then the glass vessel place inside to simulate rapid heat-up during printing. After 10 minutes the sample vessel was removed from the oil bath and the pump left running for a further five minutes, so that any additional emissions could be drawn 
through the filter. The filters were weighed before and after the tests so that the collected mass of emissions could be obtained.

Each of the filters used was initially heated to either $550^{\circ} \mathrm{C}$ or $250^{\circ} \mathrm{C}$ and then cooled in a dessicator before use. At the conclusion of sample collection the filters were removed and returned to the dessicator before being weighed. After weighing the filter was heated to $100^{\circ} \mathrm{C}$ before being returned to the dessicator and re-weighed. This process was repeated for temperatures of $150^{\circ} \mathrm{C}$ and $250^{\circ} \mathrm{C}$.

In order to approximate the amount of carbon black in the toner, an elemental analysis of both toner and Printex U was performed using a Thermo Finnigan EA 1112 Series Flash Elemental Analyser.

\subsection{PAH analysis}

Samples of carbon black and toner were analysed for PAH content. Additional samples of carbon black were heated to $250^{\circ} \mathrm{C}$ and $300^{\circ} \mathrm{C}$ and then analysed to measure any loss of PAHs through evaporation, as may occur during the printing process.

Identification of the PAHs was carried out by extraction using organic solvent, followed by pre-concentration and analysis by gas chromatography mass spectrometry (GC/MS). Control and laboratory blank samples were analysed concurrently with the toner samples.

Samples were spiked with a known amount of surrogate standard (ChemService Product CSS8250-1JM) and placed in the ASE for further extraction with 4:1 mixture of hexane and ethylacetate. The sample extracts were combined and concentrated down, a known amount of internal standard (ChemService Product PP-HC8JM) was added prior to the sample being made up to volume with equal volumes of ethylacetate and hexane. Sub-samples of the extract were analysed by GC/MS.

For the duration of this study an Agilent 6890 Gas Chromatograph (GC) coupled to a 5973 Mass Spectrometer (MS) operating in the selected ion monitoring (SIM) mode was used to carry out the analyses. The GC was fitted with a HP-5MS capillary column $(60 \mathrm{~m} \times 0.25 \mathrm{~mm} \times 0.25 \mu \mathrm{m})$. The injector was operated in the pulsed splitless mode and was held at $300^{\circ} \mathrm{C}$ with a target pulse pressure of 50 psi. After the run had been initiated the oven was held at $50^{\circ} \mathrm{C}$ for 2 minutes, the column was then heated to $240^{\circ} \mathrm{C}$ at $12^{\circ} \mathrm{C} / \mathrm{min}$ and then to $310^{\circ} \mathrm{C}$ at $3^{\circ} \mathrm{C} / \mathrm{min}$, the column was then held at this temperature for 16.5 minutes. The $\mathrm{GC}$ eluate was introduced into the $\mathrm{MS}$ via a transfer line maintained at $300^{\circ} \mathrm{C}$. The MS operated with a start 
(a)

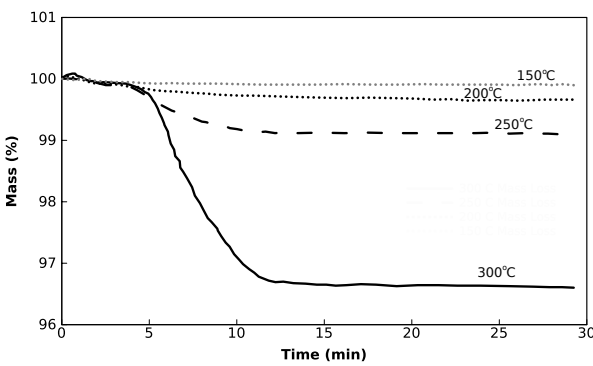
point.

\section{Results and Discussion}

delay of 10 minutes and positive electron ionization (EI) of $70 \mathrm{eV}$. To improve sensitivity the system was set to monitor five groups of ions ranging from 82 to 172 atomic mass units (amu) with a dwell time of 40 milliseconds (ms) in Group 1, to 138 to 300 amu with a $40 \mathrm{~ms}$ dwell time in Group 5. The GC/MS system was calibrated using five calibration standards, plus a zero

In order for laser printers to produce emissions (from the toner) there must be a mass loss of toner during the printing process. Figure 2 shows the mass loss of samples of toner, during the simulated printing process at different temperatures. It is clear that significant mass loss (and hence release of emissions) occurs at temperatures higher than $250^{\circ} \mathrm{C}$. There is also minimal mass loss at $150^{\circ} \mathrm{C}$, indicating minimal water and $\mathrm{VOC}$ content in the toner. The significantly higher mass loss at $300^{\circ} \mathrm{C}$, is possibly due to thermal decomposition of the binder (a styrene based polymer).

Figure 2: Mass loss of printer toner during a simulated printing process at different temperatures, (a) shows the change in the original mass of toner during the simulated printing process and, (b) shows the cumulative mass loss during heating.

This is in contrast to Printex U, which begins to lose mass at lower temperatures. This can be seen clearly in Figure 3 where results for both Printex $\mathrm{U}$ and toner are shown. All samples were heated to $250^{\circ} \mathrm{C}$. The temperature profile is shown so that the mass loss can be seen in relation to temperature. All samples lost a significant proportion of their total mass loss during heating. The higher mass loss of Printex $U$ samples at the beginning of the measurement, was attributed to the presence of moisture in the sample (despite dessication prior to analysis, which suggests a high surface area). 
In comparing the results, it should be noted that carbon black is a component of toner and therefore would be expected to show a higher mass loss than the toner itself, where it has effectively been diluted with binder. It is useful in this study, to consider Printex $U$ as it contains a higher proportion of PAHs and therefore they should be more readily measured.

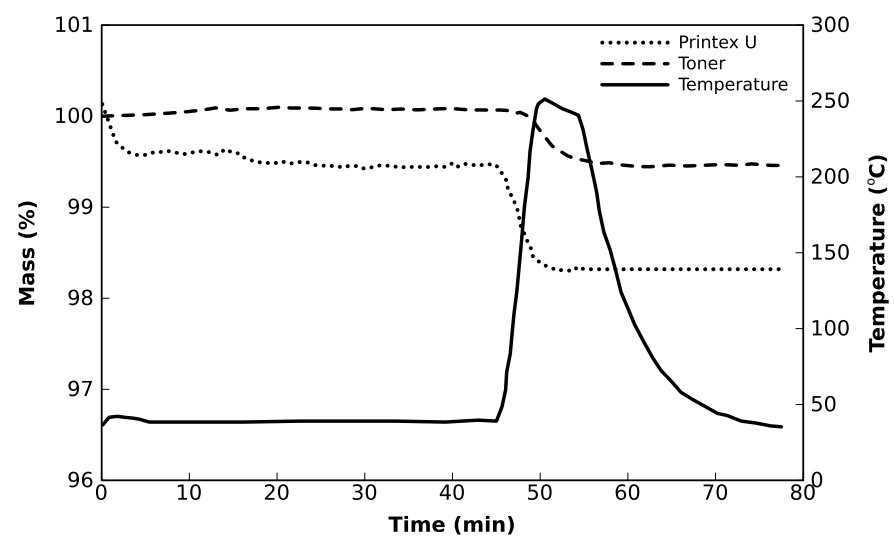

Figure 3: Mass loss of toner and Printex U samples during the simulated printing process, for 4 different maximum temperatures.

Given that printer toner contains carbon black in combination with binder and other components, the VOC and PAH analysis was carried out on the Printex U, as this is essentially the carbon black component of toner in isolation. The results of the VOC analysis are given in Table 1, where $c$ is the concentration of the compound in the carbon black (w/w).

The VOCs shown in Table 1 only make up $0.015 \%$ of the mass of Printex $\mathrm{U}$, and so are likely present in toner in very low (difficult to measure) concentrations.

The results of the PAH analysis are shown in Table 2. Multiple samples were analysed, with the resultant mean concentration, $c_{m}$, and standard deviation (SD) given. Samples of Printex U were analysed as supplied as well as after heating to $250^{\circ} \mathrm{C}$ and $300^{\circ} \mathrm{C}$. None of the PAHs present in Printex U, as supplied, were detectable in the samples heated to $300^{\circ} \mathrm{C}$, and so no data is shown in Table 2. Only compounds detected are listed, quantities indicated by $<$ were below the detection limit. The standard deviations for some of the heated samples are not listed as only one of the three samples gave a quantity over the detection limit. In these cases the concentration given is for the single measurement not a mean concentration. The large standard 
Table 1: VOC content of Printex U

\begin{tabular}{cc}
\hline Compound & $c(\mathrm{mg} / \mathrm{kg})$ \\
\hline Benzene & 30 \\
Styrene & 4.4 \\
Toluene & 95 \\
Xylene, m- \& p- & 12 \\
Xylene, o- & 0.7 \\
1,2,4-trimethylbenzene & 0.6 \\
Ethylbenzene & 0.9 \\
Chloroform & 2.8 \\
Tetrachloro-ethylene & 1.4 \\
Dichloromethane & 2.5 \\
\hline
\end{tabular}

deviations for some compounds are attributed to samples being taken from different batches of Printex U. Some individual Printex U samples showed overall PAH levels up to $5 \mathrm{x}$ that of a typical diesel engine soot (also analysed by the authors), which is concerning.

Table 2: PAH content of Printex U

\begin{tabular}{ccccc}
\hline & \multicolumn{2}{c}{ As Supplied } & After Heating to $250^{\circ} \mathrm{C}$ \\
\hline Compound & $c_{m}(\mathrm{mg} / \mathrm{kg})$ & $\mathrm{SD} \pm$ & $c_{m}(\mathrm{mg} / \mathrm{kg})$ & $\mathrm{SD} \pm$ \\
\hline Naphthalene & 70.1 & 46.0 & 5 & - \\
Acenaphthylene & 83.4 & 58.4 & $<$ & - \\
Acenaphthene & 12 & - & $<$ & - \\
Phenanthrene & 402.8 & 143.4 & 48.5 & 31.8 \\
Anthracene & 47.6 & 12.4 & $<$ & - \\
Fluoranthene & 173.3 & 73.2 & 86.5 & 33.2 \\
Pyrene & 109.4 & 50.1 & 56 & 22.6 \\
Benz(a)anthracene & 37.5 & - & $<$ & - \\
Chrysene & 30.2 & - & $<$ & - \\
Benzo(b)fluoranthene & 11 & 1.4 & 8.5 & 2.1 \\
Benzo(k)fluoranthene & 16.8 & 2.9 & 7 & - \\
Benzo(e)pyrene & 5.7 & 0.6 & $<$ & - \\
Benzo(a)pyrene & 9.5 & 5.7 & $<$ & - \\
Indeno(1,2,3-cd)pyrene & 5 & 0 & $<$ & - \\
\hline
\end{tabular}

It is evident from Table 2 that PAHs will be released when Printex U and 
hence toner is heated, as is the case in laser printers. The Printex $\mathrm{U}$ samples contained between 0.08 and $0.13 \%$ PAH by mass.

Table 3 shows the results of the PAH analysis for printer toner, again only compounds present in quantities above the detection limit are shown.

Table 3: PAH content of toner

\begin{tabular}{ccc}
\hline \multicolumn{2}{c}{ Table 3: PAH content of toner } \\
\hline Compound & $c_{m}(\mathrm{mg} / \mathrm{kg})$ & $\mathrm{SD}$ \\
\hline Phenanthrene & 5.1 & 1.7 \\
Anthracene & 5.8 & 1.7 \\
Fluoranthene & 5.9 & 0.4 \\
Pyrene & 2.7 & 1.7 \\
Benz(a)anthracene & 9.1 & - \\
Chrysene & 7.1 & - \\
Benzo(k)fluoranthene & 3.5 & 1.0 \\
Benzo(a)pyrene & 5 & 1.4 \\
\hline
\end{tabular}

Based on the results of the elemental analysis, and assuming a styrene binder (or binder with comparable hydrogen to carbon ratio) the amount of carbon black in the toner was found to be approximately $4.7 \%$. Considering the significant amount of dilution of carbon black in toner, it is not surprising that fewer PAHs were detectable in the toner samples. These are mostly the compounds present in the highest concentrations in Printex U.

In order to relate these results back to 'real world' printing we consider the rate of printing and toner consumption for a typical office printer. For our given printer (see Section 2) the results of toner consumption tests are shown in Table 4, where toner usage per page is shown in relation to a percentage of page coverage. Alternatively, we can also express toner consumption in relation to a unit printed area (100\% coverage), which in this case is 6.19 $\mu \mathrm{g} / \mathrm{cm}^{2}$.

Using the manufacturers listed printing rate of 35 pages/minute and assuming a $10 \%$ coverage per page, the $\mathrm{PAH}$ emissions in relation to printing time are estimated at $82.1 \mu \mathrm{g} \mathrm{PAH} /$ minute. It should be noted that this would be an overestimate as this assumes that all PAHs are emitted to air. In reality, it is likely that given the proximity of the paper to the fuser roller, some (or most) of the PAHs emitted will be absorbed by the paper. The other consideration is that the heating of the toner by the fuser roller will likely be more rapid than in the simulated printing process we have used, which may lead to reduced emissions. The estimate provided here should be 
Table 4: Toner consumption during printing

\begin{tabular}{ccc}
\hline$\%$ page coverage & toner used $(\mathrm{mg} / \mathrm{page})$ & $\mathrm{PAH}^{*}(\mu \mathrm{g} / \mathrm{page})$ \\
\hline 5 & 19.19 & 1.17 \\
10 & 38.39 & 2.35 \\
15 & 57.58 & 3.52
\end{tabular}

* Estimated value, based on carbon black composition. The majority of PAH emitted would remain in the printed area or be absorbed into the paper.

treated as a 'worst case scenario' and indicates that we need at least to be aware of PAH emissions from printers, or PAH levels absorbed into printed paper.

The results of our work may also be compared to results in the literature of measured printer emissions. Wang et al. (2011) measured the emissions of VOCs during printing, calculating total VOC emissions of $2.14 \mathrm{mg}$, over a 1000 page print cycle, giving $2.14 \mu \mathrm{g} /$ page. Based on our VOC analysis of carbon black, we estimate VOC emissions of $2.7 \mu \mathrm{g} /$ page. The difference between the two values is likely due to a difference in compositions in the VOC components of the toner used by Wang et al. (2011) and carbon black. With that considered, the two results agree well.

To further confirm the release of compounds from toner, large scale tests were conducted. These tests heated the toner and collected any particulate produced in a filter. Toner mass losses during these tests were equivalent to those given in Figure 2(a). An increase in mass in the filter was observed indicating the presence of such substances in toner emissions. After initial weighing, the filters were heated, then weighed. It was found that all collected emissions could be evaporated from the filter at or before $250^{\circ} \mathrm{C}$. The results are shown in Figure 4.

It can be seen in Figure 4 that all mass collected by the filter is driven off at $250^{\circ} \mathrm{C}$. On this basis, and given the known presence of PAHs and VOCs it is assumed that all collected emissions are either, water, SVOCs or PAHs. Given that over $80 \%$ of the mass collected on the filter is still present after heating to $100^{\circ} \mathrm{C}$, it is assumed that the majority of the emissions are VOCs and PAHs. Additionally, based on the results of the VOC analysis, where the only (detected) compound with a boiling point above $150^{\circ} \mathrm{C}$ was $1,2,4$ trimehtylbenzene, we propose that the majority of the collected emissions are PAHs. We do note however, that during the printing process, long chain 


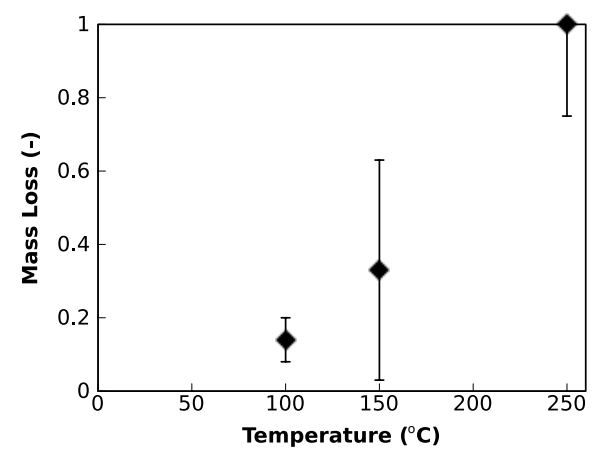

Figure 4: Cumulative mass loss from the filters, each data point represents a mean value, with error bars indicating $\pm 1 \mathrm{SD}$

alkanes and siloxanes have been detected by other authors (Barthel et al., 2011; Morawska et al., 2009). These however, are considered to be too volatile (and in too low concentrations) to form persistent particles (Morawska et al., 2009) and so were not specifically tested for. Furthermore, the carbon and/or toner contains no silicon and therefore siloxanes must have another source (such as printer components - therefore presumably more of an issue with newer printers). This leads to the interesting question of source (and generation mechanism) apportionment of printer emissions, which is however beyond the scope of this work.

We have only considered the evaporation-condensation mechanism of aerosol formation, neglecting additional mechanical forces. Other forces (mechanical, electrostatic) and processes exist, which may serve to either generate additional particles, or collect those generated from heating and fusing toner.

\section{Conclusion}

This work identified 14 different PAHs in toner and its constituents. A number of these were released during a simulated printing process and are therefore likely to be released during normal laser printing operations. We have estimated maximum possible PAH emissions at $82.1 \mu \mathrm{g} /$ minute for $10 \%$ page coverage at 35 pages/minute. Due to differences between the actual printing process and our simulated printing process actual emissions are expected to be lower than this estimate. As manufacturers are beginning to use lower printing temperatures the amount of PAHs released will likely be 
decreased. Nevertheless it may be advisable for carbon black manufacturers to attempt to reduce PAH levels on their products. and more consideration given to PAHs.

\section{Acknowledgements}

The authors would like to acknowledge Thomas Jeffreys (AERC) for assistance with the TGA measurements, the ChemCentre WA, for assistance with the PAH analysis and Dr Thomas Rodemann of the Central Science Laboratory at the University of Tasmania for the elemental analysis.

\section{References}

Barthel, M., Pedan, V., Hahn, O., Rothhardt, M., Bresch, H., Jann, O., Seeger, S., 2011. Xrf-analysis of fine and ultrafine particles emitted from laser printing devices. Environmental Science \& Technology 45, 7819-7825.

Bredin, A., Larcher, A. V., Mullins, B. J., 2011. Thermogravimetric analysis of carbon black and engine soot - towards a more robust oil analysis method. Tribology International 44, 1642-1650.

Gminski, R., Decker, K., Heinz, C., Seidel, A., Könzcöl, M., Goldenberg, E., Grobéty, B., Ebner, W., Gieré, R., Mersch-Sundermann, V., 2011. Genotoxic effects of three selected black toner powders and their dimethyl sulfoxide extracts in cultured human epithelial a549 lung cells in vitro. Environmental and Molecular Mutagenesis 52, 296-309.

Hänninen, O., Brüske-Hohfeld, I., Loh, M., Stoeger, T., Kreyling, W., Schmid, O., Peters, A., 2010. Occupational and consumer risk exstimates for nanoparticles emitted by laser printers. Journal of Nanoparticle Research 12, 91-99.

He, C., Morawska, L., Taplin, L., 2007. Particle emission characteristics of office printers. Environmental Science \& Technology 41, 6039-6045.

He, C., Morawska, L., Wang, H., Jayaratne, R., McGarry, P., Johnson, G. R., Bostrom, T., Gonthier, J., Authemayou, S., Ayoko, G., 2010. Quantification of the relationship between fuser roller temperature and laser printer emissions. Journal of Aerosol Science 41, 523-530. 
Kagi, N., Fujii, S., Horiba, Y., Namiki, N., Yoshio, O., Emi, H., Tamura, H., Kim, Y., 2007. Indoor air quality for chemical and ultrafine particle contaminants from printers. Building and Environment 42, 1949-1954.

Koivisto, A. J., Hussein, T., Niemelä, R., Tuomi, T., Hämeri, K., 2010. Impact of particle emissions of new laser printers on a modeled office room. Atmospheric Environment 44, 2140-2146.

Könzcöl, M., Weiß, A., Gminski, R., Merfort, I., Mersch-Sundermann, V., 2013. Oxidative stress and inflammatory response to printer toner particles in human epithelial a549 lung cells. Toxicology Letters 216, 171-180.

Lee, C.-W., Dai, Y.-T., Chien, C.-H., Hsu, D.-J., 2006. Characterisitics and health impacts of volatile organic compounds in photocopy centers. Environmental Research 100, 139-149.

Lee, C.-W., Hsu, 2007. Measurements of fine and ultrafine particles formation in photocopy centers in taiwan. Atmospheric Environment 41, 6598-6609.

Lee, S. C., Lam, S., Fai, H. K., 2001. Characterization of vocs, ozone, and $\mathrm{pm}_{10}$ emissions from office equipment in an environmental chamber. Building and Environment 36, 837-842.

Morawska, L., He, C., Johnson, G. R., Jayaratne, R., Salthammer, T., Wang, H., Uhde, E., Bostrom, T., Modini, R., Ayoko, G., McGarry, P., Wensing, M., 2009. An investigation into the characterisitics and formation mechanisms of particles originating from the operation of laser printers. Environmental Science \& Technology 43, 1015-1022.

Schripp, T., Wensing, M., Uhde, E., Salthammer, T., He, C., Morawska, L., 2008. Evaluation of ultrafine particle emissions from laser printers using emission test chambers. Environmental Science \& Technology 42, 43384343 .

Stoeger, T., Reinhard, C., Tekenaka, S., Schroeppel, A., Karg, E., Ritter, B., Heyder, J., Schulz, H., 2006. Instillation of six different ultrafine carbon particles indicates a surface are threshold dose for acute lung inflammation in mice. Environmental Health Perspectives 114, 328-333. 
Straif, K., Baan, R., Grosse, Y., Secretan, B., El Ghissassi, F., Cogliano, V., 2005. Carcinogenicity of polycyclic aromatic hydrocarbons. The Lancet Oncology 6, 931-932.

Tang, T., Gminski, R., Könzcöl, M., Modest, C., Armbruster, B., MerschSundermann, V., 2012a. Investigations on cytotoxic and genotoxic effects of laser printer emissions in human epithelial a549 lung cells using an air/liquid exposure system. Environmental and Molecular Mutagenesis 53, $125-135$.

Tang, T., Hurraß, J., Gminski, R., Mersch-Sundermann, V., 2012b. Fine and ultrafine particles emitted from laser printers as indoor air contaminants in german offices. Environmental Sciene and Pollution Research 19, 38403849 .

Wang, Z.-M., Wagner, J., Wall, S., 2011. Characterization of laser printer nanoparticle and voc emissions, formation mechanisms, and strategies to reduce airborne exposure. Aerosol Science and Technology 25, 1060-1068.

Wensing, M., Schripp, T., Uhde, E., Salthammer, T., 2008. Ultra-fine particles release from hardcopy devices: Sources, real-room measurements ans efficiency of filter accessories. Science of the Total Environment 407, 418427.

Wolkoff, P., Nielsen, G. D., 2001. Organic compounds in indoor air - their relevance for perceived indoor air quality? Atmospheric Environment 35, $4407-4417$. 